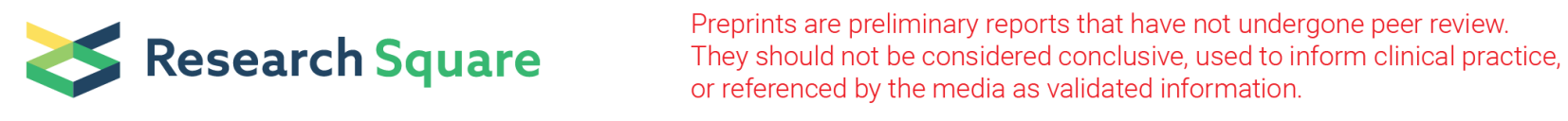

\title{
Hepatic Perivascular Epithelioid Cell Neoplasms: An Analysis of 16 Cases
}

\author{
Yubin Fu ( $\square$ f15639277697@163.com ) \\ Zhengzhou University First Affiliated Hospital \\ Jiahao Xue \\ Zhengzhou University First Affiliated Hospital \\ Penglei Ge \\ Zhengzhou University First Affiliated Hospital \\ Rufei Guo \\ Zhengzhou University First Affiliated Hospital \\ Lin Li \\ Zhengzhou University First Affiliated Hospital \\ Chen Li \\ Institute of Basic Medical Sciences

\section{Zhengkai Feng} \\ Zhengzhou University First Affiliated Hospital \\ Chunbo Li \\ Zhengzhou University First Affiliated Hospital \\ Yang Wu \\ Zhengzhou University First Affiliated Hospital
}

Research Article

Keywords: liver, perivascular epithelioid cell tumors, PEComa, immunohistochemistry, therapy

Posted Date: May 20th, 2021

DOI: https://doi.org/10.21203/rs.3.rs-529501/v1

License: (c) (1) This work is licensed under a Creative Commons Attribution 4.0 International License. Read Full License 


\begin{abstract}
Background: Hepatic perivascular epithelioid cell neoplasm (Hepatic PEComa) is a rare type of mesenchymal tumor and its diagnosis and treatment are controversial. To investigate its clinical features and to guide the diagnosis and treatment of this tumor.
\end{abstract}

Methods: Retrospectively analysing the clinical data of 16 patients with pathologically confirmed hepatic PEComa, who were admitted to the First Affiliated Hospital of Zhengzhou University from April 2014 to April 2020, and summarizing its clinical symptoms, Imaging features, histological and immunohistochemical characteristics, therapy and prognosis.

Results: All 16 patients were female, aged from 23 to 65 years (mean, $44 \pm 12$ years). Clinical manifestations, preoperative routine laboratory tests and imaging examinations were lack of specificity. Immunohistochemical results showed that the positive rates of HMB-45, Melan-A and SMA were 100\% (16/16), 100\% $(16 / 16)$ and $81.3 \%(13 / 16)$ respectively. The negative rates of Hepatocytes and S-100 were $100 \%(16 / 16)$ and $75 \%(12 / 16)$, respectively. With regard to treatment, eleven patients had undergone "laparotomy for partial hepatectomy" or "laparoscopic partial hepatectomy". Three patients had undergone "radiofrequency ablation of liver tumors". One patient had undergone chemotherapy with the " gemcitabine + nedaplatin + apatinib " regimen. Twelve of sixteen patients were followed up for 6- 55 months (mean, $26 \pm 18$ months), one case of an intrahepatic recurrent lesion was found 14 months after radiofrequency ablation of liver tumors, and the remaining 11 cases showed no enlargement of the primary lesion, and no new lesions, metastasis or death.

Conclusions: Hepatic PEComa lacks specific clinical manifestations and imaging features. The diagnosis depends on histological and immunohistochemical characteristics. The positive of HMB-45, Melan-A, and SMA and the negative of S-100 are helpful in the diagnosis of hepatic PEComa. Most hepatic PEComas are benign lesions, and radical resection is the best treatment with a favorable prognosis.

\title{
Introduction
}

Perivascular epithelioid cell tumors (PEComas) are rare mesenchymal tumors composed of perivascular epithelioid cells (PECs) with distinct histological and immunohistochemical characteristics [1]. PEComas are distributed widely throughout the body and are commonly observed in the retroperitoneum, gastrointestinal tract, uterus, soft tissue, kidneys, skin, bone and other organs [2]. Clinically, hepatic PEComas are very rare and most cases are reported in case reports. Due to the lack of specific clinical manifestations and imaging features, no uniform diagnostic and treatment criteria exist. We retrospectively analyzed the clinical data of 16 patients with hepatic perivascular epithelioid cell tumors, who were admitted to the First Affiliated Hospital of Zhengzhou University from April 2014 to April 2020, especially the clinical manifestations,imaging features and treatment of the tumors, to improve the understanding of hepatic PEComas and guide the diagnosis and treatment of this tumor.

\section{Methods \\ Clinical data}

We collected the clinical data of 16 patients with pathologically confirmed hepatic PEComa, who were admitted to the First Affiliated Hospital of Zhengzhou University from April 2014 to April 2020. All 16 patients had complete clinical data, including data on gender, age, family history, clinical symptoms and signs, routine blood composition tests, liver and renal function tests, tumor markers (AFP, CEA and CA19-9), and ultrasound, CT and/or MRI features. The pathological and immunohistochemical results of all the patients were confirmed by more than 2 pathologists according to WHO criteria. The institutional approval and informed consent were obtained for this study.

\section{Treatments}

Fourteen of sixteen patients had undergone surgical treatments under general anesthesia: 9 patients had undergone "partial hepatectomy", 2 patients had undergone "laparoscopic partial hepatectomy". During the operation, no metastatic lesions were detected in the abdominal cavity, and the liver was fully dissociated. Three patients had undergone "radiofrequency ablation of liver tumors" after the diagnosis of liver biopsy. One patient only accepted the "gemcitabine + nedaplatin + apatinib" chemotherapy regimen after the diagnosis by liver biopsy, and another patient accepted "liver biopsy" under local anesthesia only because of the occurrence of multiple liver metastases and the patient's willingness. Follow-up data were obtained by referring to medical records and telephone calls, and the follow-up deadline was April 21, 2020.

\section{Statistical analysis}

All analyses were carried out using IBM SPSS Statistics software (version 26)

\section{Results}

\section{General information and clinical manifestations}

All 16 patients were female, aged from 23 to 65 years (mean, $44 \pm 12$ years). Among them, 11 patients had no obvious clinical symptoms, and were incidentally detected during physical examination; 4 patients presented nonspecific gastrointestinal symptoms, including abdominal pain, abdominal distension and loss of appetite; 1 patient was detected due to the pain in the right kidney. The tumors in 15 patients were solitary lesions, among which 12 were located in the right lobe of the liver and 3 in the left lobe of the liver. One case had multiple lesions in both-side lobes of the liver with kidney PEComa. Laboratory tests, including routine blood composition tests, renal function tests, and analysis of tumor markers (AFP, CEA and CA-199), were all within the 
normal range in 16 patients. Thirteen patients had normal liver function. One patient had a history of hepatitis $\mathrm{B}$, and the remainder had no history of viral hepatitis (HBV, HCV) or tuberous sclerosis complex (TSC). (Table 1)

\section{Imaging features}

All 16 patients had undergone ultrasonography, 9 patients had CT, 10 patients had MRI, and 3 patients had both CT and MRI. Most tumors were round (11/16), with well-defined margins (12/16), internal heterogeneity (15/16), and often contained dysmorphic vessels (10/16). Only one tumor contained very little fat. The maximum diameter of tumors ranged from 1.0 to $19.8 \mathrm{~cm}$ (mean $5.7 \mathrm{~cm}$ ). No portal vein or biliary system was invaded in $16 \mathrm{cases,} \mathrm{and} \mathrm{no} \mathrm{abnormal}$ lymph node or distant metastasis was found. Most ultrasonic manifestations were solid hypoechoic nodules with heterogeneous echogenicity in the tumors (12/16). Nonenhanced CT showed that the tumors were mostly round, with well-defined margins and heterogeneous low-density shadows (Fig. 1A). Contrastenhanced CT showed remarkable heterogeneous enhancement in the arterial phase (9/9) (Fig. 1B), and the enhancement in the venous phase showed different degrees of reduction compared with that of the arterial phase (9/9) (Fig. 1C). In nonenhanced MRI images, tumors mainly presented hypointense signals in T1WI (Fig. 2A) and hyperintense signals in fat-suppressed T2WI (Fig. 2B) and DWI (Fig. 2C). Contrast-enhanced MRI images presented heterogeneous enhancement in the arterial phase (10/10) (Fig. 2D), 9 of 10 cases showed various enhancement attenuation patterns in the portal (Fig. 2E) and delayed phases, while one presented persistent enhancement in the portal and delayed phases. Regarding the clinical manifestations and imaging features, 11 patients were misdiagnosed with hepatocellular carcinoma (HCC) before surgery, 2 with hepatic adenoma (HCA), 1 with hepatic hemangioma, 1 with hepatic metastatic tumor, and 1 with hepatic hamartoma.

\section{Pathological findings}

Pathologically, the surgical margins of 11 patients with partial hepatectomy were all negative. The cut surface of the tumors was gray-red, gray-yellow or graywhite, soft, solid or cystic and solid. The pathological results of HE staining showed that the tumor was composed of epithelioid cells and dilated blood vessels. The PECs were round or polygonal, with bright or mildly eosinophilic cytoplasm, the nuclei were clear, pleomorphic, and had prominent nucleoli. The epithelioid cells were arranged around the blood vessels, and the vascular lumen expanded irregularly. There were no clear necrosis and lymphatic vascular invasion (Fig. 3). Immunohistochemical detection was performed for all 16 pathological specimens, and the positive rate of $\mathrm{HMB}-45$ and Melan-A was $100 \%$ $(16 / 16)$, the positive rate of SMA was $81.3 \%(13 / 16)$, the positive rate of CD34 was $93.8 \%(15 / 16)$, the positive index of Ki67 ranged from $1-20 \%$, the negative rate of Hepatocyte was 100\% (16/16), and the negative rate of S-100 was 75\% (12/16) (Table 2) (Fig. 4).

\section{Follow-up results}

Fourteen of sixteen patients in our group were followed up, and the follow-up time was $6-55$ months (mean, $26 \pm 18$ months), During the follow up, one case of intrahepatic recurrent lesion was found 14 months after radiofrequency ablation of liver tumors, The remaining 13 cases showed no enlargement of the primary lesion, and no new lesions, metastasis or death were observed.

\section{Discussion}

PEComas are a rare type of mesenchymal tumor. In 1992, Bonetti et al.[3] first defined "PEC" as an unusual cell type that was immunoreactive with melanocyte markers, and had an epithelioid appearance, a clear-acidophilic cytoplasm, and a perivascular distribution. In 1996, Zamboni G et al.[4] reported that these tumors occurred in different sites and comprised perivascular epithelioid cells (PECs) with similar morphological characteristics and phenotypes as PEComas. In 2013, The World Health Organization (WHO) [5] defined PEComas as "mesenchymal tumors composed of distinctive cells that show a focal association with blood vessel walls and usually express melanocytic and smooth-muscle markers" in the fourth edition of the classification of soft tissue and bone tumors. The PEComa family include angiomyolipoma (AML), clear cell "sugar" tumor of the lung (CCST), lymphangioleiomyomatosis (LAM), and a group of tumors that is similar in histology and immunophenotype in various organs and soft tissues (NOS). Clinically, angiomyolipomas (AMLs) with little or no fat are usually termed PEComas [6, 7]. All 16 patients in this group were diagnosed with hepatic PEComas by pathology and immunohistochemistry, among whom 15 cases were found to be fat-free and 1 case contained less fat.

Hepatic PEComas mostly present in middle-aged women and are likely related to hormone levels [8]. Most hepatic PEComas are single lesions, usually located in the right lobe of the liver, while multiple lesions are comparatively rare. The routine laboratory tests, including routine blood composition tests, live and renal function tests, and analysis of tumor biomarkers (including AFP, CEA, CA19-9 and CA125) are generally within the normal range. Most patients are asymptomatic and show no significant correlation with hepatitis virus history or cirrhosis [9], while some present nonspecific gastrointestinal symptoms, such as upper abdominal discomfort, abdominal pain, abdominal distension, loss of appetite, which may be caused by the increasing size of the tumor resulting in the tension of liver capsule or compression of surrounding organs [10, 11]. However, Da Tang [12] reported that the clinical symptoms are independent of tumor size, and patients with small tumors may also develop clinical symptoms. Consistent with our study, among the 16 female patients, the tumors of 12 patients were located in the right lobe of the liver. Eleven patients had no subjective symptoms and were incidentally detected during physical examination. Nonspecific upper abdominal discomfort was found in 4 patients, and 1 patient was found because of pain in the right kidney area. Among 16 patients, only 1 patient was complicated with hepatitis $B$ virus infection.

There are no typical imaging findings of hepatic PEComa. Most tumors show heterogeneous low-density shadows in nonenhanced CT images, hypointense signals in T1WI images and hyperintense signals in fat-suppressed T2WI and DWI images in nonenhanced MRI images [13]. Contrast-enhanced CT or MRI mainly shows marked heterogeneous enhancement in the arterial phase and washout in the portal and delayed phases, while persistent enhancement was observed in a few cases [6]. Regarding our study, most lesions were hypoechoic in ultrasound images (12/16). On contrast-enhanced CT or MRI, all 16 cases presented heterogeneous enhancement in the arterial phase; among whom, 15 cases showed various enhancement attenuation patterns in the portal and delayed phases (15/16), and 1 case presented with persistent enhancement (1/16). The proportion of different components within the tumors may lead to different enhancement patterns, making it difficult to diagnose through radiological examination. For example, when contrast agent empties rapidly in the

Page 3/10 
equilibrium phase, it is likely to be misdiagnosed with HCC or metastasis, a finding that may be related to hypervascularity and arteriovenous connections; however, when the contrast agent is slowly discharged or with persistent enhancement in the equilibrium phase, it will be difficult to distinguish it from other benign liver tumors, such as hepatic adenoma, hepatic hemangioma and FNH [10, 13].All 16 patients in our study were misdiagnosed with HCC, hepatic adenoma, hepatic hemangioma, hepatic metastasis or undiagnosed lesions before surgery. Therefore, hepatic PEComa should be considered for those patients with the above imaging features.

The diagnosis of hepatic PEComa is mainly dependent on pathology and immunohistochemistry [14]. Microscopically, the tumor mainly comprises epithelioid cells (PECs) with abundant clear eosinophilic granular cytoplasm radially arranged around the vascular lumen [13-15]. However, the histogenesis and pathogenesis of PECs have not been elucidated; one hypothesis is that PECs may originate from undifferentiated neural crest cells that express melanocytes and smooth muscle cell phenotypes $[8,13,16]$. The PEComa family possesses similar immunohistochemical phenotypes. Almost all PEComas show positive expression of both HMB-45 and SMA markers. Nevertheless, studies have indicated only $80 \%$ of cases show co-expression of both; thus, the diagnosis of PEComa cannot be excluded only because SMA expression is negative[17]. In addition to HMB-45 and SMA, some additional immunohistochemical markers with positive expression, such as Melan-A, SMA, vimentin, S-100, Desmin, CD31, and CD34, and those with negative expression, including CgA, Syn, CK, CD117, CD10, AFP and EMA, are helpful to confirm the diagnosis but not completely coincidental [8]. Consistent with the above, all 16 cases in our group were positive for HMB-45 and Melan-A, 13 cases for SMA, and 15 cases for CD34. Twelve cases were negative for S-100.

PEComas possess a wide range of biological behaviors, and most are benign. However, the uniform standard to evaluate the malignant degree of PEComas has not yet been fully established [6]. In 2005, Folpe et al. [18] proposed the criteria to classify PEComa of soft tissues into benign, malignant and uncertain

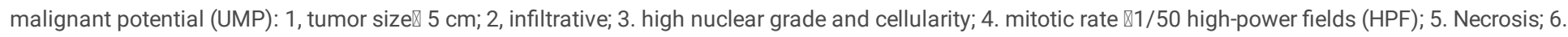
vascular invasion. PEComas with two or more of the above features were considered malignant, and only those with nuclear pleomorphism and a tumor size $]$ $5 \mathrm{~cm}$ were considered to have an uncertain malignancy potential. However, studies have confirmed that, although these histological features suggest malignancy, distant metastases were not found [7]. Hao b-b et al. [19] summarized the similarities and differences of benign and malignant hepatic PEComas, and pointed out that malignant hepatic PEComas should contain the following characteristics: 1. Female patient older than 50 years; 2 . abdominal discomfort or pain; 3. tumor diameter $>10 \mathrm{~cm}$; 4, positive expression for CD34 and Ki67; 5. Negative expression for CD117. Because malignant cases of hepatic PEComa are rare, further studies are needed to improve the criteria to differentiate between benign and malignant cases.

Due to its rarity and malignant tendency, the treatment of hepatic PEComa has been controversial. Several literature sources have suggested that patients with hepatic PEComa with no clinical symptoms and serologic abnormalities, a tumor diameter $₫ 5 \mathrm{~cm}$, and benign histological features, may only consider regular review [15]. However, it has also been reported that postoperative recurrence and metastasis still occur in patients with hepatic PEComa with benign histologic features [20]. Thus, for resectable tumors by preoperative evaluation, radical resection is a preferred therapeutic method with a favorable prognosis. Of the 16 patients with hepatic PEComa in this group, 11 had undergone "laparotomy for partial hepatectomy" or "laparoscopic partial hepatectomy", and the postoperative pathological examinations were RO resection; 3 patients had undergone "radiofrequency ablation of liver tumors" after the diagnosis by liver biopsy, and none of them had surgical complications or death. For temporarily unresectable hepatic PEComas, stereotactic body radiation therapy (SBRT) or transcatheter arterial embolization (TAE) can be used to shrink the tumor size to a resectable range for surgical treatment [14, 21]. A few PEComas may be associated with TSC $[13,16]$, and the pathogenesis of PEComa is mainly caused by the mutation or deletion of TSC1 (9q34) or TSC2 (16p13), leading to high expression of mTOR pathway components and promotion of excessive cell proliferation. Therefore, it is helpful to shrink the tumor size in patients of TSCassociated hepatic PEComa who accept preoperative neoadjuvant therapy with mTOR inhibitors[22]. For advanced unresectable or metastatic hepatic PEComas, systemic therapies including anti-angiogenesis agents (sorafenib, apatinib, and sunitinib), cytotoxic chemotherapy (gemcitabine or anthracyclinebased regimens) or mTOR inhibitors such as sirolimus, may be effective. However, due to the lack of published prospective clinical trials and sufficient retrospective cases, the reactivity to tumors and median progression-free survival (PFS) have not yet been determined [23]. Considering the large size of the tumor and pathological indication of malignant lesions, 1 patient in this group accepted the chemotherapy regimen of "gemcitabine + nedaplatin + apatinib" and the tumor shrank by $2 \mathrm{~cm}$ after 6 months. The natural history and prognosis of hepatic PEComa are not entirely clear at present, and malignant cases usually metastasize early; thus, all patients with hepatic PEComa need long-term close follow up [11, 12]. Fourteen of sixteen patients in this group were followed up regularly, and the longest follow-up time was up to 55months. During the follow-up period, only one case of intrahepatic recurrent lesion was found 14 months after radiofrequency ablation of liver tumors.

\section{Conclusion}

Hepatic PEComa is a rare mesenchymal tumor that lacks specific clinical manifestations and imaging features and is difficult to be diagnosed before surgery. The diagnosis of hepatic PEComa is mainly dependent on the pathology and immunohistochemistry. Radical resection is the preferred treatment. For patients with unresectable or metastatic disease, the options are radiofrequency ablation, TAE, antiangiogenic agents (e.g., sorafenib, apatinib, and sunitinib), cytotoxic chemotherapy (gemcitabine or anthracycline-based regimens), or mTOR inhibitors, such as sirolimus). All patients with hepatic PEComas require long-term follow-up to assess tumor reactivity and the median progression-free survival (PFS).

\section{Abbreviations}

PEComa, perivascular epithelioid cell tumor; PECs, perivascular epithelioid cells; AFP, alpha-fetoprotein; CEA, carcinoembryonic antigen; CA19-9, carbohydrate antigen 19-9; CA125, carbohydrate antigen 125; TSC, tuberous sclerosis complex; HCC, hepatocellular carcinoma; HCA, hepatic adenoma; HMB-45, human melanoma black-45; SMA, smooth muscle actin; HBV, hepatitis B virus; HCV, hepatitis C virus; AML, angiomyolipoma; CCST, clear cell "sugar" tumor; LAM, lymphangioleiomyomatosis; ALT, aminotransferase; AST, aspartate aminotransferase; FNH, focal nodular hyperplasia; SBRT, stereotactic body radiation therapy; TAE, transcatheter arterial embolization 


\section{Declarations}

\section{Acknowledgements}

This research was supported by Joint Construction Project of Henan Medical Science and Technology Research Program (grant number LHGJ20190136).

This study was performed at the First Affiliated Hospital of Zhengzhou University, Zhengzhou. This study used data from the First Affiliated Hospital of

Zhengzhou University, Zhengzhou.

We thank AJE (www.aje.com) for the editorial touch-up of this manuscript.

\section{Authors' contributions:}

Yubin Fu and Penglei Ge put forward the idea of this study and collected, analyzed the data and wrote the article. Yubin Fu, Rufei Guo and Chen Li searched literatures. Penglei Ge, Lin Li and Yang Wu reviewed the manuscript and gave important professional advice. Rufei Guo, Chen Li, Zhengkai Feng, Chunbo Li, Jiahao Xue wrote the article. Yang Wu approved the final version of the article. Yubin Fu is the guarantor.

\section{Funding:}

This research was supported by Joint Construction Project of Henan Medical Science and Technology Research Program (grant number LHGJ20190136).

\section{Availability of data and materials:}

The data that support the fundings of this study are available frome the corresponding author (Yang Wu, MD, PhD) on request.

\section{Ethics approval and consent to participate:}

This study was approved by the Ethics Committee of The First Affiliated Hospital of Zhengzhou University, No. 1 Jianshe East Road, Zhengzhou, Henan Province, China. All procedure performed in studies were in accordance with the Declaration of Helsinki.

\section{Consent for publication:}

This study was approved by the Ethics Committee of The First Affiliated Hospital of Zhengzhou University, No. 1 Jianshe East Road, Zhengzhou, Henan Province, China.

Since the study was conducted anonymously, no consent to publication by the patient was required.

\section{Competing interests:}

All our authors have no conflicts of interest to disclose.

\section{References}

1. Mitchell A, Jordan A, Lewit R, Kruse E: Perivascular Epithelioid Cell Tumor of the Liver. Am Surg 2018, 84(9):e428-e430.

2. !!! INVALID CITATION !!! [2, 3].

3. Bonetti F, Pea M, Martignoni G, Zamboni G: PEC and sugar. Am J Surg Pathol 1992, 16(3):307-308.

4. Zamboni G, Pea M, Martignoni G, Zancanaro C, Faccioli G, Gilioli E, Pederzoli P, Bonetti F: Clear cell "sugar" tumor of the pancreas. A novel member of the family of lesions characterized by the presence of perivascular epithelioid cells. Am J Surg Pathol 1996, 20(6):722-730.

5. Fletcher CDM, Bridge JA, Hogendoorn PCW, Mertens F: WHO Classification of Tumours of Soft Tissue and Bone. In., 4th edn. Lyon: IARC; 2013 : $230-231$.

6. Han X, Sun M-Y, Liu J-H, Zhang X-Y, Wang M-Y, Fan R, Qamar S: Computed tomography imaging features of hepatic perivascular epithelioid cell tumor: A case report and literature review. Medicine (Baltimore) 2017, 96(49):e9046-e9046.

7. Maebayashi T, Abe K, Aizawa T, Sakaguchi M, Ishibashi N, Abe O, Takayama T, Nakayama H, Matsuoka S, Nirei K et al: Improving recognition of hepatic perivascular epithelioid cell tumor: Case report and literature review. World J Gastroenterol 2015, 21(17):5432-5441.

8. Kirnap M, Ozgun G, Moray G, Haberal M: Perivascular epithelioid cell tumor outgrowth from the liver. Int J Surg Case Rep 2018, 53:295-298.

9. Ma Y, Huang P, Gao H, Zhai W: Hepatic perivascular epithelioid cell tumor (PEComa): analyses of 13 cases and review of the literature. Int $J$ Clin Exp Pathol 2018, 11(5):2759-2767.

10. Hekimoglu K, Haberal M: Liver Perivascular Epithelioid Cell Tumor with an Unusual Location: Diagnostic Characteristics with Multidetector Computed Tomography and Magnetic Resonance Imaging. J Clin Imaging Sci 2017, 7:36-36. 
11. Abhirup B, Kaushal K, Sanket M, Ganesh N: Malignant hepatic perivascular epithelioid cell tumor (PEComa) - Case report and a brief review. J Egypt Natl Canc Inst 2015, 27(4):239-242.

12. Tang D, Wang J, Tian Y, Li Q, Yan H, Wang B, Xiong L, Li Q: Hepatic perivascular epithelioid cell tumor: Case report and brief literature review. Medicine (Baltimore) 2016, 95(51):e5572-e5572.

13. Nie P, Wu J, Wang H, Zhou R, Sun L, Chen J, Yang G: Primary hepatic perivascular epithelioid cell tumors: imaging findings with histopathological correlation. Cancer Imaging 2019, 19(1):32-32.

14. Guan H, Zou Y, Lv Y, Wang C: Hepatic perivascular epithelioid cell tumor treated by transarterial embolization plus radiofrequency ablation: A case report and literature review. Medicine (Baltimore) 2017, 96(22):e6969-e6969.

15. Chen W, Liu Y, Zhuang Y, Peng J, Huang F, Zhang S: Hepatic perivascular epithelioid cell neoplasm: A clinical and pathological experience in diagnosis and treatment. Mol Clin Oncol 2017, 6(4):487-493.

16. Bao L, Shi Y, Zhong J, Zhao M, Wu J, Hai L, Xu X, Du H, Shi Y: Histopathologic characteristics and immunotypes of perivascular epithelioid cell tumors (PEComa). Int J Clin Exp Pathol 2019, 12(12):4380-4389.

17. Liu Z, Qi Y, Wang C, Zhang X, Wang B: Hepatic perivascular epithelioid cell tumor: five case reports and literature review. Asian J Surg 2015, 38(1):58-63.

18. Folpe AL, Mentzel T, Lehr H-A, Fisher C, Balzer BL, Weiss SW: Perivascular epithelioid cell neoplasms of soft tissue and gynecologic origin: a clinicopathologic study of 26 cases and review of the literature. Am J Surg Pathol 2005, 29(12):1558-1575.

19. Hao B-B, Rao J-H, Fan Y, Zhang C-Y, Dai X-Z, Li X, Leng Y, Zhang F: Hepatic perivascular epithelioid cell tumor in three patients. Hepatobiliary Pancreat Dis Int 2016, 15(6):660-664.

20. Parfitt JR, Bella AJ, Izawa JI, Wehrli BM: Malignant neoplasm of perivascular epithelioid cells of the liver. Arch Pathol Lab Med 2006, 130(8):1219-1222.

21. Kirste S, Kayser G, Zipfel A, Grosu A-L, Brunner T: Unresectable hepatic PEComa: a rare malignancy treated with stereotactic body radiation therapy (SBRT) followed by complete resection. Radiat Oncol 2018, 13(1):28-28.

22. Bergamo F, Maruzzo M, Basso U, Montesco MC, Zagonel V, Gringeri E, Cillo U: Neoadjuvant sirolimus for a large hepatic perivascular epithelioid cell tumor (PEComa). World J Surg Oncol 2014, 12:46-46.

23. Sanfilippo R, Jones RL, Blay J-Y, Le Cesne A, Provenzano S, Antoniou G, Mir O, Fucà G, Fumagalli E, Bertulli R et al: Role of Chemotherapy, VEGFR Inhibitors, and mTOR Inhibitors in Advanced Perivascular Epithelioid Cell Tumors (PEComas). Clin Cancer Res 2019, 25(17):5295-5300.

\section{Tables}




\begin{tabular}{|c|c|c|c|c|c|c|c|c|c|c|c|c|c|}
\hline \multirow{3}{*}{ No. } & \multirow{3}{*}{ Sex } & \multirow{3}{*}{ Age } & \multirow{3}{*}{$\mathrm{HBV} / \mathrm{HCV}$} & \multicolumn{10}{|c|}{ Table 1. General data of the 16 cases of hepatic PEComa } \\
\hline & & & & \multirow[t]{2}{*}{ Symptom } & \multirow[t]{2}{*}{$\begin{array}{l}\text { Associated } \\
\text { diseases }\end{array}$} & \multicolumn{2}{|c|}{$\begin{array}{l}\text { Liver } \\
\text { function }\end{array}$} & \multirow{2}{*}{$\begin{array}{l}\text { Tumoral } \\
\text { markers } \\
\text { \AFP } \\
\text { CEA } \\
\text { CA19-9区 }\end{array}$} & \multirow{2}{*}{$\begin{array}{l}\text { preoperative } \\
\text { diagnosis }\end{array}$} & \multicolumn{3}{|l|}{ Tumor } & \multirow[t]{2}{*}{ Treatment } \\
\hline & & & & & & ALT & AST & & & Location & Number & $\begin{array}{l}\text { Size } \\
(\mathrm{cm})\end{array}$ & \\
\hline 1 & $\mathrm{~F}$ & 48 & None & $\begin{array}{l}\text { No } \\
\text { symptom }\end{array}$ & None & 16 & 21 & Normal & $\mathrm{HCA}$ & $\begin{array}{l}\text { Right } \\
\text { lobe }\end{array}$ & 1 & 3.0 & $\begin{array}{l}\text { Laparotomy for } \\
\text { partial } \\
\text { hepatectomy }\end{array}$ \\
\hline 2 & $\mathrm{~F}$ & 35 & None & $\begin{array}{l}\text { No } \\
\text { symptom }\end{array}$ & None & 12 & 16 & Normal & $\mathrm{HCA}$ & $\begin{array}{l}\text { Right } \\
\text { lobe }\end{array}$ & 1 & 2.3 & $\begin{array}{l}\text { Laparotomy for } \\
\text { partial } \\
\text { hepatectomy }\end{array}$ \\
\hline 3 & $\mathrm{~F}$ & 47 & None & $\begin{array}{l}\text { No } \\
\text { symptom }\end{array}$ & Hypertension & 12 & 15 & Normal & $\mathrm{HCC}$ & $\begin{array}{l}\text { Right } \\
\text { lobe }\end{array}$ & 1 & 8.4 & $\begin{array}{l}\text { Laparotomy for } \\
\text { partial } \\
\text { hepatectomy }\end{array}$ \\
\hline 4 & $\mathrm{~F}$ & 47 & None & $\begin{array}{l}\text { Pain in the } \\
\text { right } \\
\text { kidney } \\
\text { area }\end{array}$ & $\begin{array}{l}\text { Kidney } \\
\text { PEComa }\end{array}$ & 10 & 17 & Normal & $\begin{array}{l}\text { Liver } \\
\text { metastases }\end{array}$ & $\begin{array}{l}\text { Right } \\
\text { lobe and } \\
\text { left lobe }\end{array}$ & $\llbracket 3$ & 2.2 & Liver biopsy \\
\hline 5 & $\mathrm{~F}$ & 33 & None & $\begin{array}{l}\text { No } \\
\text { symptom }\end{array}$ & None & 17 & 16 & Normal & $\begin{array}{l}\text { Hepatic } \\
\text { hemangioma }\end{array}$ & $\begin{array}{l}\text { Right } \\
\text { lobe }\end{array}$ & 1 & 19.8 & $\begin{array}{l}\text { Laparotomy for } \\
\text { partial } \\
\text { hepatectomy }\end{array}$ \\
\hline 6 & $\mathrm{~F}$ & 33 & None & $\begin{array}{l}\text { No } \\
\text { symptom }\end{array}$ & None & 91 & 32 & Normal & $\mathrm{HCC}$ & Left lobe & 1 & 6.1 & $\begin{array}{l}\text { Laparotomy for } \\
\text { partial } \\
\text { hepatectomy }\end{array}$ \\
\hline 7 & $\mathrm{~F}$ & 65 & None & $\begin{array}{l}\text { No } \\
\text { symptom }\end{array}$ & None & 12 & 17 & Normal & $\mathrm{HCC}$ & $\begin{array}{l}\text { Right } \\
\text { lobe }\end{array}$ & 1 & 3.9 & $\begin{array}{l}\text { Laparotomy for } \\
\text { partial } \\
\text { hepatectomy }\end{array}$ \\
\hline 8 & $\mathrm{~F}$ & 52 & None & $\begin{array}{l}\text { No } \\
\text { symptom }\end{array}$ & None & 133 & 86 & Normal & $\mathrm{HCC}$ & $\begin{array}{l}\text { Right } \\
\text { lobe }\end{array}$ & 1 & 4.8 & $\begin{array}{l}\text { Radiofrequency } \\
\text { ablation of liver } \\
\text { tumors }\end{array}$ \\
\hline 9 & $\mathrm{~F}$ & 55 & None & $\begin{array}{l}\text { No } \\
\text { symptom }\end{array}$ & None & 17 & 19 & Normal & $\mathrm{HCC}$ & $\begin{array}{l}\text { Right } \\
\text { lobe }\end{array}$ & 1 & 4.3 & $\begin{array}{l}\text { Laparoscopic } \\
\text { partial } \\
\text { hepatectomy }\end{array}$ \\
\hline 10 & $\mathrm{~F}$ & 64 & None & $\begin{array}{l}\text { Abdominal } \\
\text { distension, } \\
\text { poor } \\
\text { appetite }\end{array}$ & hypertension & 18 & 25 & Normal & $\mathrm{HCC}$ & $\begin{array}{l}\text { Right } \\
\text { lobe }\end{array}$ & 1 & 3.5 & $\begin{array}{l}\text { Laparotomy for } \\
\text { partial } \\
\text { hepatectomy }\end{array}$ \\
\hline 11 & $\mathrm{~F}$ & 50 & None & $\begin{array}{l}\text { No } \\
\text { symptom }\end{array}$ & $\begin{array}{l}\text { Hypertension } \\
\text { and diabetes }\end{array}$ & 10 & 11 & Normal & $\begin{array}{l}\text { Liver } \\
\text { hamartoma }\end{array}$ & $\begin{array}{l}\text { Right } \\
\text { lobe }\end{array}$ & 1 & 3.9 & $\begin{array}{l}\text { Radiofrequency } \\
\text { ablation of liver } \\
\text { tumors }\end{array}$ \\
\hline 12 & $\mathrm{~F}$ & 30 & $\mathrm{HCV}$ & $\begin{array}{l}\text { Abdominal } \\
\text { distension, } \\
\text { poor } \\
\text { appetite }\end{array}$ & None & 755 & 606 & Normal & $\mathrm{HCC}$ & $\begin{array}{l}\text { Right } \\
\text { lobe }\end{array}$ & 1 & 4.3 & $\begin{array}{l}\text { Radiofrequency } \\
\text { ablation of liver } \\
\text { tumors }\end{array}$ \\
\hline 13 & $\mathrm{~F}$ & 48 & None & $\begin{array}{l}\text { No } \\
\text { symptom }\end{array}$ & None & 10 & 12 & Normal & $\mathrm{HCC}$ & $\begin{array}{l}\text { Right } \\
\text { lobe }\end{array}$ & 1 & 17.0 & $\begin{array}{l}\text { Gemcitabine + } \\
\text { Nedaplatin + } \\
\text { Apatinib }\end{array}$ \\
\hline 14 & $\mathrm{~F}$ & 34 & None & $\begin{array}{l}\text { No } \\
\text { symptom }\end{array}$ & None & 12 & 13 & Normal & $\mathrm{HCC}$ & $\begin{array}{l}\text { Right } \\
\text { lobe }\end{array}$ & 1 & 3.7 & $\begin{array}{l}\text { Laparotomy for } \\
\text { partial } \\
\text { hepatectomy }\end{array}$ \\
\hline 15 & $\mathrm{~F}$ & 47 & None & $\begin{array}{l}\text { Abdominal } \\
\text { pain }\end{array}$ & None & 12 & 13 & Normal & $\mathrm{HCC}$ & Left lobe & 1 & 2.7 & $\begin{array}{l}\text { Laparotomy for } \\
\text { partial } \\
\text { hepatectomy }\end{array}$ \\
\hline 16 & $\mathrm{~F}$ & 55 & None & $\begin{array}{l}\text { Abdominal } \\
\text { pain }\end{array}$ & None & 9 & 16 & Normal & $\mathrm{HCC}$ & Left lobe & 1 & 1.8 & $\begin{array}{l}\text { Laparoscopic } \\
\text { partial } \\
\text { hepatectomy }\end{array}$ \\
\hline
\end{tabular}


Table 2

Immunohistochemical results of the 16 cases of hepatic PEComa

\begin{tabular}{|c|c|c|c|c|c|c|c|}
\hline No. & HMB-45 & Melan-A & SMA & CD34 & Hepatocyte & S-100 & Ki67囚+囚 \\
\hline 1 & + & + & + & + & - & - & $20 \%$ \\
\hline 2 & + & + & + & + & - & + & $3 \%$ \\
\hline 3 & + & + & + & + & - & + & $1 \%$ \\
\hline 4 & + & + & - & + & - & - & $10 \%-20 \%$ \\
\hline 5 & + & + & + & + & - & - & $5 \%$ \\
\hline 6 & + & + & + & - & - & - & $5 \%$ \\
\hline 7 & + & + & + & + & - & - & $5 \%$ \\
\hline 8 & + & + & + & + & - & - & $5 \%$ \\
\hline 9 & + & + & + & + & - & - & $10 \%$ \\
\hline 10 & + & + & + & + & - & - & $5 \%$ \\
\hline 11 & + & + & - & + & - & + & $1 \%$ \\
\hline 12 & + & + & + & + & - & - & $5 \%$ \\
\hline 13 & + & + & + & + & - & - & $5 \%$ \\
\hline 14 & + & + & + & + & - & + & $1 \%$ \\
\hline 15 & + & + & - & + & - & - & $3 \%$ \\
\hline 16 & + & + & + & + & - & - & $5 \%$ \\
\hline
\end{tabular}

\section{Figures}
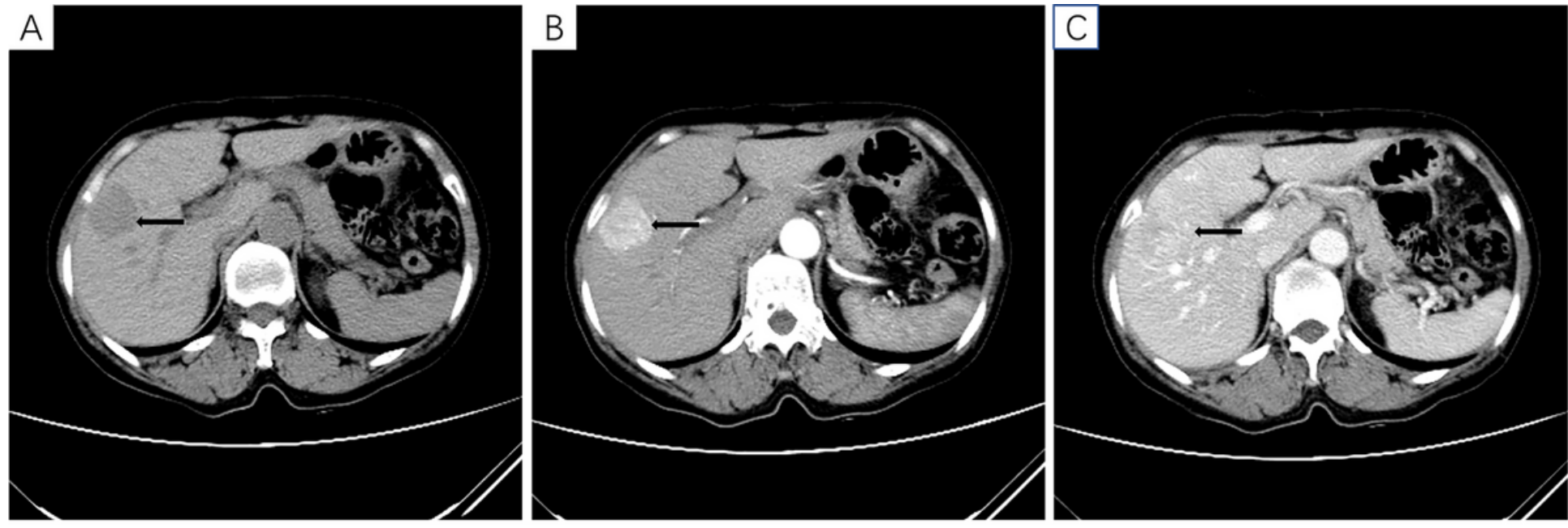

Figure 1

CT image of hepatic PEComa. (A) Nonenhanced CT showed no obvious abnormalities in the size and shape of the liver, and the right lobe of the liver showed circular low-density areas with unclear boundaries (black arrow). (B) Dynamic contrast-enhanced scan showed various enhancement in the arterial phase (black arrow). (C) arterial venous phase was relatively low density (black arrow). 

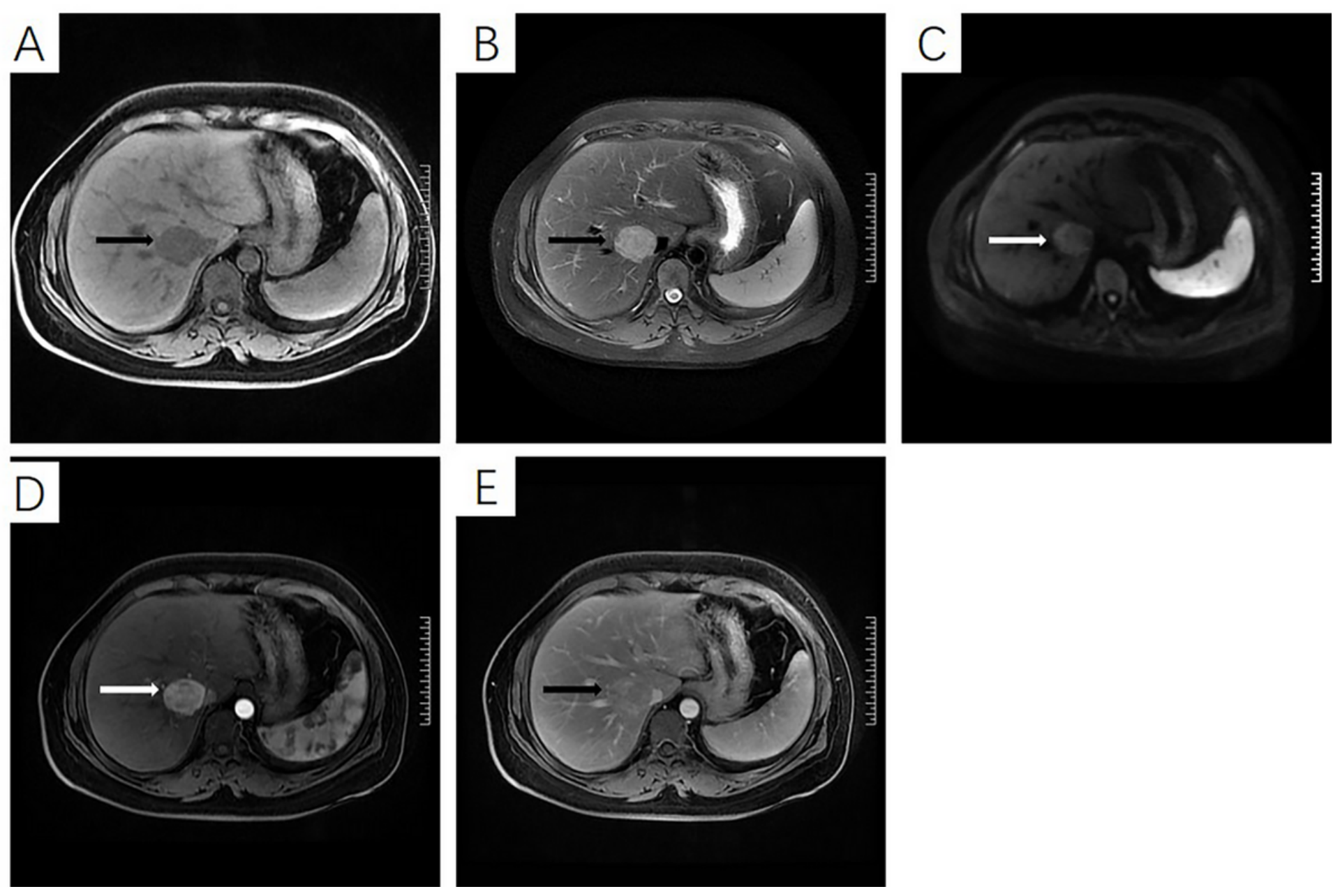

Figure 2

Magnetic Resonance Imaging characteristics of hepatic PEComa. (A) T1WI, showing a hypointense signal mass in the upper segment of the right posterior lobe of the liver, with well-defined margin (black arrow). (B) T2WI, showing slightly high signal intensity of the mass (black arrow). (C) DWI demonstrates that the mass showed high signal intensity with high b value and limited diffusion (white arrow). (D) Dynamic contrast-enhanced scan shows obvious enhancement of the lesion in the arterial phase and the lesion is closed to the inferior vena cava (white arrow). (E) Portal venous phase, indicating a decrease in signal intensity of the lesion (black arrow). PEComa, perivascular epithelioid cell tumor; T1WI, T1-weighted imaging; T2WI, T2-weighted imaging; DWI, diffusion-weighted imaging.

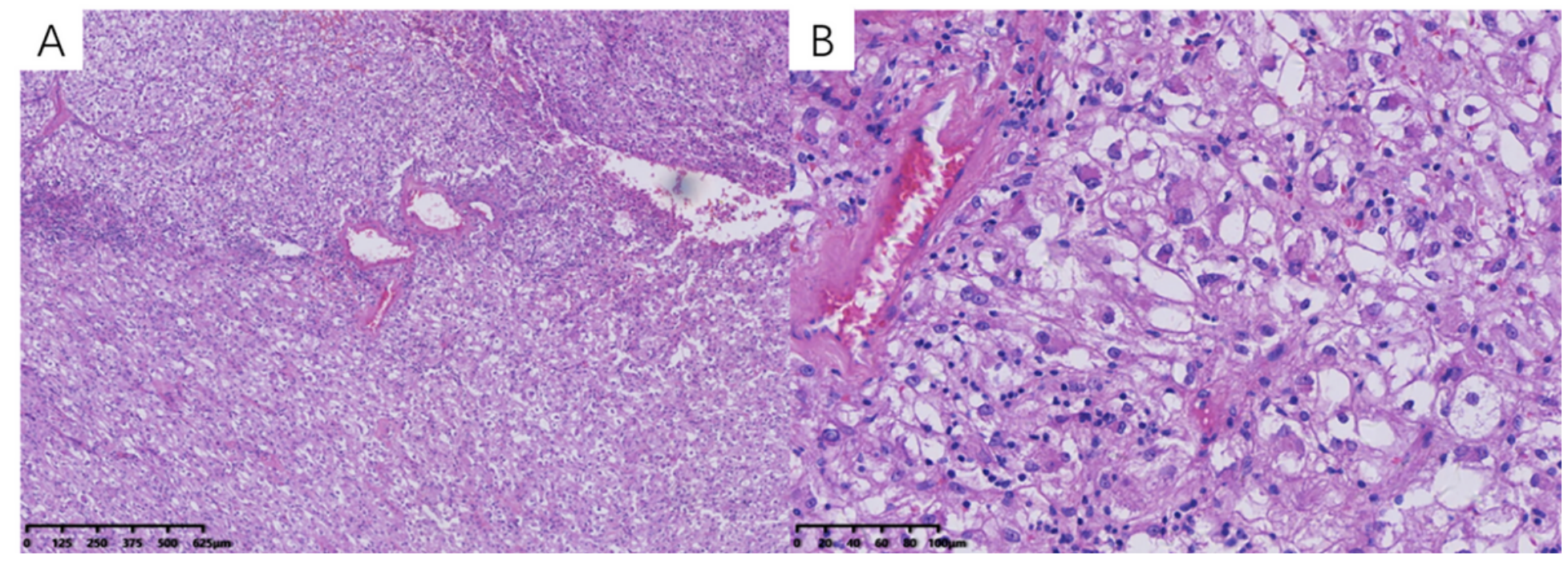

Figure 3 
The histologic features of hepatic PEComa. (A) The tumor was mainly composed of PECs and dilated blood vessels, and there were no clear necrosis and lymphatic vascular invasion; magnification, $x 40$. (B) The PECs were round or polygonal, with bright or mildly eosinophilic cytoplasm, the nuclei were clear, pleomorphic, and had prominent nucleoli; magnification, x200.

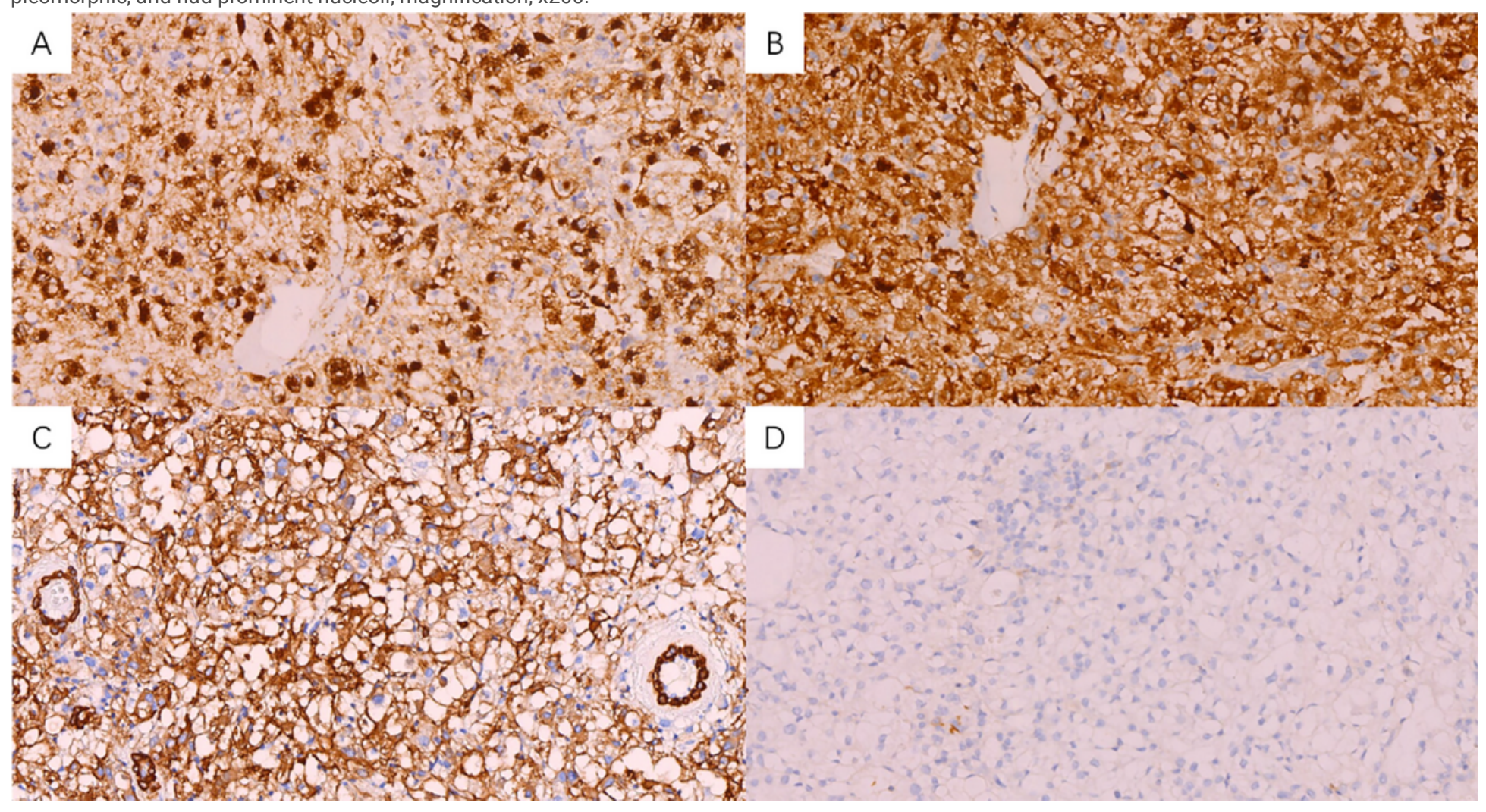

\section{Figure 4}

The immunohistochemical features of hepatic PEComas. All 16 cases were positive for HMB-45 (A) and Melan-A (B), 13 cases for SMA (C), 12 cases were negative for S-100 (D); magnification, $x 200$. 